\title{
The nation's diet in context: the future
}

\section{By D. H. Shrimpton*, 'Crangon', Bucks Lane, Little Eversden, Cambridge CB3 7HL.}

For the purpose of the discussion which follows, the future is defined in two stages: first for 10 years and second for 50 years. The 10-year scenario is dominated by short-term issues and is within the long-range forecasting of major companies. Indeed many will have plans for 5 years developed in some detail and so one may conclude that the major options are already established and that dramatic and unforeseen change, at least after 5 years, is unlikely. For the second part of the decade there will be a new government, with the possibility of a different political philosophy and hence change from governmental action. Nevertheless in the remainder of the decade it is reasonable to assume that even if the rate of change is faster than in the first 5-year period, it is unlikely to lead to results that differ substantially from the forecasts made at the outset.

The second scenario of 50 years is different and accurate forecasting is not possible. However, one can seek to identify the factors which could give rise to change, evaluate them and project the more likely and less likely scenarios from the analysis. This is the approach that is followed here.

Both scenarios are considered in relation to their likely impact on livestock production.

\section{The 10-year scenario}

The major factors are: political, industrial, and consumer preferences. In the UK a new government took office in 1987 and hence it is reasonable to suppose that its policies will continue for 5 years. These are characterized by minimal intervention in the affairs of industry and the individual, advocating the solution of problems through 'market forces'. It is assumed in this discussion that this scenario will not be challenged by major war or by domestic political upheaval, and that consequently the new government in the middle of the decade will either continue the current policies or change them in an evolutionary manner. On this basis it is assumed that the political environment will be broadly constant through the decade, recognising that if there is change, it will start to become effective towards the end of the decade under discussion.

Two developments have made a major impact on the food industry and hence on the types of food available to the public in Britain. First, the dramatic advances in food technology and transportation have made the entire world available as a source of supply to the British market. This international character of supply has been mirrored in the organization of the food manufacturing industry which is now dominantly international, both in its sources of finance and its management; but it is not suggested that the relation is causal, although it is fortuitous and of considerable importance. Second, the supermarkets have developed so far that they are now the companies which dominate the patterns of manufacture and the price structure.

The consumer in Britain is materialistic and hedonistic and accustomed to exercising choice on a wide range of commodities and goods of international provenance with little sign of national loyalty. Within this there is a growing awareness of a relation between diet and health, but there is also reason to suppose that this awareness is clouded by nutritional ignorance. It is not unreasonable to assume that during the decade the level of knowledge and understanding will improve, and that as a consequence there will be fewer dramatic changes and a steady but more consistant change towards the guidelines

*Honorary Research Fellow, Department of Community Medicine, University of Bristol. 
of the National Advisory Committee on Nutrition Education (1983) report and the specific recommendations of the Committee on Medical Aspects of Food Policy (COMA) report (Department of Health and Social Security, 1984) on diet in relation to cardiovascular disease. Indeed, at the official level, the majority of the Health Districts in the UK have already moved in this direction, and commercially there is now a wide range of goods from which a healthy, varied and enjoyable diet may be selected.

\section{Implications for livestock production}

National and international recommendations to reduce the intake of saturated fats in order to reduce the incidence of cardiovascular disease have been widely misinterpreted, leading some to exclude animal products from their diet and others to consider that any vegetable oil is good for health. Yet in the first decades of the century George Bernard Shaw was writing routinely to enquirers as follows: 'Mr Bernard Shaw's vegetarian correspondents are reminded that vegetarianism does not mean living on vegetables' (quoted by Fowden, 1980).

The late Sir John Hammond was amongst the first to recognize the importance of genetics and diet on the body composition of the pig, demonstrating that leanness could be increased through breed selection and dietary manipulation (Hammond \& Murray, 1937). Later, Harrington \& Pomeroy (1954) repeated the study on the genetically more advanced pigs of the post-war years and developed the study into a proposition of general relations. This early work has enabled more recent workers in research and in the livestock industry to respond to pressure from the supermarkets, in turn interpreting a change in the mood of the public into market opportunity, to produce low-fat meat.

Although the balance between the very lean meats of birds and the red meats may continue to change in favour of the former, it does not seem likely that there will be a major reduction in the total consumption of meat on a per capita basis in the UK within a decade. Further, continuing research to produce leaner red-meat animals may even arrest the growth in the market share of poultry. However, the future for meat products may well be different and become one of decline once their high content of saturated fats becomes more generally recognised, unless there are substantial changes in their formulation.

\section{The 50-year scenario}

An indication of the order of magnitude of the change that could take place is given from an examination of the past 50 years. By a fortunate chance this symposium has met on the 50th anniversary of the publication of the second edition of Lord Boyd-Orr's survey of the adequacy of diet in relation to income (Orr, 1937). This publication, which included the reports of expert committees on the findings of the Boyd Orr survey (Orr, 1936) recorded poverty of diet in the midst of plenty in pre-war Britain. Today there is a comparable situation internationally, with mass starvation in parts of the world co-existing with massive surpluses of primary foods in other areas. This situation cannot be overlooked when considering the 50 -year scenario.

The nutritional deprivation of the 1930s in Britain changed dramatically and rapidly during the period of the Second World War. During this period of national emergency there was a requirement to use limited supplies of food to ensure that the population was healthy. Hammond (1951) has concluded that the acceptance of optimum, rather than minimum, standards of feeding as the aim of policy and the stabilization of supply, prices and wages offered full scope for activity that was more than a mere holding situation. The redistribution of primary foods eliminated nutritional deprivation in the population. Nevertheless, Hammond (1951) warned against attributing to scientific influence changes 
that resulted from the pressure of events; an injunction that also applies to predictions for the ensuing 50 years.

Irrespective of the balance between science and events, the scale of dietetic change in Britain in 50 years has been substantial, and it is against the evidence of the feasibility of substantial change in the nutritional status of a nation that the future will be considered. Nutritional factors will be considered in the context of the environment of the population and with particular reference to the influence that forecast change might have on livestock production.

\section{Demography}

England and Wales. The dominant characteristic is that of an ageing population. By 2001 the index of ageing will almost have doubled to give 9.4 million over 60 years of age compared with 1.8 million in 1931 (Davis, 1976). A major influence on this prediction will be the effect of preventive medicine on survival and, in particular, on the influence of change in lifestyle, including diet, on the numbers who survive beyond middle age.

Western Europe. There is a similar prediction, with the proportion of the population over 65 years of age ranging between 14 and $17 \%$ in the major countries. This compares with $4.2 \%$ in neighbouring Turkey (Gisser, 1985). The society is affluent and protective, as in Britain, and is moving towards greater cohesion, with the possibility that an isolationist policy could develop with an apparent indifference to world food problems.

International. Here the population is dominated by the inhabitants of Asia and Africa who, in the year 2000 , will account for approximately $60 \%$ of the population of the world. This population is dominantly vegetarian, from force of circumstance, and in some respects is similar to the British population studied by Boyd Orr. The wealthy minority are, as a group, meat eaters (except where religion prevents this) and are well nourished; but the percentage in this fortunate category is small and nowhere near Boyd Orr's $50 \%$ in Britain. Undoubtedly there is a potential for power and change in this situation.

\section{Science}

The rapidly advancing technology associated with experimental science raises the prospect of being able to quantify conditions of optimal nutrition which, as a concept, formed the basis of nutritional advice in the Second World War in the UK. Should this occur, one might expect significant change in the recommendations for the consumption of nutrients, including maxima as well as minima. Provided there is a comparable development in education of the public there is no reason to conclude from present knowledge that such an approach would in itself result in a substantial reduction in the demand for livestock for food.

The 'optimal' approach is almost universally applied in the commercial feeding of farm animals. However, the techniques used to acquire the quantitative information to make this approach possible are all invasive and hence of limited application in the nutrition of the human being. Moreover, they have been applied to situations where the response is unambiguous and quantifiable; chiefly growing, reproducing and lactating animals.

In the human being, quality of life and the associated mental attributes are the characteristics which are of major interest, assuming that symptoms of clinical deficiency are absent; and these are the very characteristics that are difficult to define and measure to the satisfaction of the biochemically trained nutritionist. However, recently there has been an attempt to begin to resolve this problem for micro-ingredients in a study on school children in Wales (Benton \& Roberts, 1988). 
A major current question is that of the possibility that lifestyle, including diet, in youth influences health in middle age. Hence current lifestyles may influence the health of the population towards the end of the 50-year period under review. Whilst this hypothesis has the attraction of being capable of providing an explanation of some current observations on the onset of diet-related chronic diseases, there is no proof of causality. However, a longitudinal study was begun in 1970 (Butler et al. 1982) which is being developed in such a way that information acquired can be expected to contribute towards a greater understanding of this situation by the researchers of the future. Meanwhile, the assumption is made that the population will slowly continue along a pathway of progressive moderation of the current excesses of the Western-style diet. However, whilst the population mean may change over the 50 -year period, there is no reason to suppose that there will be change in maxima and minima of the distribution curve, with the implied consequence of a continuing but smaller demand for products that are high in saturated fat and low in digestible fibre.

One further area of biology will be considered in this section: livestock production as part of an agricultural system. Miller (1980) calculated that only $57 \%$ of primary crop production was available for human consumption because of the low efficiency, on an energy basis, of livestock; quoted by Miller (1980) as an average of $17.5 \%$. This low value results from the weighting of the information in recognition of the dominance of ruminants in the livestock population of the world, but it does not take account of the inability of human beings to utilize many of the pastures consumed by ruminants and consequently made available to them through the intervention of the ruminant. $A$ positive weighting to take account of this would have a major effect on the overall average and would inevitably lead to a re-evaluation of the role of the ruminant as an integral part of the system of food supply for the human population. Unfortunately in the UK there has been, until recently, a trend towards the intensive management and feeding of ruminants, utilizing cereals which can be utilized directly by humans and so vitiating the strength of the nutritional argument in their favour.

A different perspective on this argument has been presented by Blaxter (1986) who has shown that in the world as a whole a family of four is accompanied, on a statistical basis, by 1.3 cattle or buffalo, 1.6 pigs, 0.7 sheep and six poultry. The challenge to the food supplies of the human being comes not from the livestock but from the inequalities, on a world basis, of the distribution of primary crops.

\section{Political}

In a projection over 50 years it is impossible to make valid political predictions, but one can draw attention to the likely impact of particular philosophies. In the UK there is a philosophy of non-intervention which also has support in some other countries. Should this remain as the dominant attitude in major Western countries through the next half century, then change will be slow, since it will depend chiefly on market forces.

Although this discussion is limited to the UK, it is unreal to omit any consideration of possible changes in attitude in the major population groups of the world, accounting for two-thirds of its population and currently deprived but developing. If change here resulted in effective redistribution of world resources, then one might speculate that a short-term effect (within 50 years) would be to continue the current expansion in the production of pigs and poultry, because: (1) the cereals for feeding them would be available from the West, (2) their products are widely desired, (3) they can produce cash crops for export, (4) their production is associated with the high standard of living of the West. In this case one might envisage a world-wide increase in the population of pigs and 
poultry, with a stabilization or even decline in their numbers in the UK, with ruminants being raised primarily by grazing.

Whilst an alternative scenario is change by revolution instead of by evolution, this is not considered in the present discussion because, by its very nature, its course is unpredictable.

\section{Conclusions}

In the short term, 10 years, there is little reason to expect a change in attitude that is so large that it will have a major effect on livestock production. There may, however, be economic and political factors which could exert such an effect and, should this occur, they would dominate any nutritional considerations. The current signs that eating habits are starting to evolve towards a pattern that, in respect of health, is likely to be advantageous, are likely to lead to a slow evolution of diet less dependent on animal fats. However, with the knowledge of livestock production that is already available, there is no cause on purely nutritional grounds to assume that livestock products will be substantially reduced in the market place.

In the longer term of 50 years there is some reason to expect greater change. The extent to which it will be rational will depend in part on a change within the UK to an interventionist policy in respect of nutritional education and, in the Third World, a development towards the redistribution of primary crops through evolution and not by revolution.

The ruminant will retain its place, and possibly strengthen it, provided its ability to utilize grazing and feeds that are unavailable to human beings is exploited. However, in the earlier part of the period one may expect that a consequence of redistribution of primary crops will result in their use in part to improve the feeding standards, and hence the productivity, of ruminants as well as an expansion in the production of the 'cash crop' simple-stomached animals.

For the UK these scenarios all point to the advantage of developing a non-food use for dairy fat.

\section{REFERENCES}

Benton, D. \& Roberts, G. (1988). Lancet I, 140-143.

Blaxter, K. (1986). People, Food and Resources. Cambridge: Cambridge University Press.

Butler, N. R., Golding J., Haslum, M. N. \& Stewart-Brown, S. (1982). Journal of the Royal Sociery of Medicine 75, 781-784.

Davis, N. (1976) Population Trends no. 3. London: H.M. Stationery Office.

Department of Health and Social Security (1984). Diet and Cardiovascular Disease. Commintee on Medical Aspects of Food Policy. Report of the Panel on Diet in Relation to Cardiovascular Disease. London: H.M. Stationery Office.

Fowden, L. (1980). In Food Chains and Human Nutrition. [K. Blaxter, editor]. London: Applied Science Publishers.

Gisser, R. (1985). Population Trends 41, 21.

Hammond, J. \& Murray, G. N. (1937). Journal of Agricultural Science, Cambridge 27, 394-431.

Hammond, R. J. (1951). History of the Second World War-Food 1. London: H.M. Stationery Office.

Harrington, G. \& Pomeroy R. W. (1954). Journal of Agricultural Science, Cambridge 45, 431-451.

Miller, D. S. (1980). In Food Chains and Human Nutrition, p. 23 [K. Blaxter, editor]. London: Applied Science Publishers.

National Advisory Committee on Nutrition Education (1983). Proposals for Nutritional Guidelines for Health Education in Britain. London: Health Education Council.

Orr, J. B. (1936). Food Health \& Income. London: Macmillan \& Co.

Orr, J. B. (1937). Food Health \& Income. London: Macmillan \& Co.

Printed in Great Britain 